\title{
Multiparty cooperation and performance in international equity joint ventures
}

Yadong Luo and

Seung Ho Park
Journal of International Business Studies (2004) 35, 335-336.

doi: 10.1 057/palgrave.jibs.8400097

Correction to: Journal of International Business Studies (2004) 35, 142-160. doi: 10.1057/palgrave.jibs. 8400072

In the above paper, an incorrect version of Table 2 was published. The correct version appears on the following page. 
Table 2 Moderated hierarchical regression results for the cooperation-performance relations $(N=250)^{a, b}$

\begin{tabular}{|c|c|c|c|c|c|c|c|c|c|}
\hline \multirow[t]{2}{*}{ Variables } & \multicolumn{3}{|c|}{ EJV performance assessment } & \multicolumn{3}{|c|}{ Foreign performance assessment } & \multicolumn{3}{|c|}{ Chinese performance assessment } \\
\hline & (1) & (2) & (3) & (4) & (5) & (6) & (7) & (8) & (9) \\
\hline $\begin{array}{l}\text { Foreign \& local } \\
\text { parent cooperation } \\
\text { (X1) }\end{array}$ & $0.56(0.09)^{\star \star \star}$ & $0.47(0.08)^{\star * *}$ & $0.36(0.07)^{\star \star *}$ & $0.34(0.08)^{\star \star \star}$ & $0.36(0.07)^{\star * *}$ & $0.29(0.10)^{\star *}$ & $0.55(0.10)^{\star \star *}$ & $0.50(0.10)^{\star \star \star}$ & $0.31(0.09)^{\star \star \star}$ \\
\hline $\begin{array}{l}\text { Local parent \& EJV } \\
\text { cooperation }(X 2)\end{array}$ & $0.05(0.07)$ & $0.05(0.07)$ & $0.05(0.07)$ & $-0.05(0.06)$ & $-0.06(0.06)$ & $-0.05(0.08)$ & $0.34(0.08)^{\star * *}$ & $0.29(0.09)^{\star \star}$ & $0.20(0.10)^{\star \star}$ \\
\hline $\begin{array}{l}\text { Foreign parent \& EJV } \\
\text { cooperation }(X 3)\end{array}$ & $0.14(0.07)^{\star}$ & $0.13(0.06)^{\star}$ & $0.11(0.08)^{\dagger}$ & $0.31(0.07)^{\star * *}$ & $0.27(0.07)^{\star * *}$ & $0.21(0.09)^{\star *}$ & $-0.07(0.08)$ & $0.04(0.08)$ & $-0.07(0.07)$ \\
\hline Goal incongruence & $-0.11(0.04)^{*}$ & $-0.10(0.05)^{\dagger}$ & $-0.12(0.06)^{*}$ & $-0.13(0.03)^{\star \star}$ & $-0.14(0.03)^{\star}$ & $-0.11(0.04)^{\star}$ & $-0.10(0.03)^{\star}$ & $-0.09(0.05)^{\star}$ & $-0.09(0.04)^{\dagger}$ \\
\hline $\begin{array}{l}\text { Structural } \\
\text { uncertainty }\end{array}$ & $-0.08(0.07)$ & $-0.08(0.07)$ & $-0.06(0.10)$ & $-0.08(0.08)$ & $-0.03(0.08)$ & $-0.04(0.09)$ & $-0.07(0.07)$ & $-0.06(0.07)$ & $-0.08(0.09)$ \\
\hline Equity stake & $0.04(0.04)$ & $0.03(0.04)$ & $0.04(0.05)$ & $0.06(0.04)$ & $0.06(0.04)$ & $0.07(0.04)$ & $0.05(0.04)$ & $0.05(0.04)$ & $0.05(0.04)$ \\
\hline Year of formation & $-0.17(0.03)^{\star *}$ & $-0.16(0.03)^{\star *}$ & $-0.15(0.03)^{*}$ & $-0.12(0.02)^{\star}$ & $-0.11(0.03)^{\star}$ & $-0.10(0.02)^{\star}$ & $-0.15(0.02)^{\star *}$ & $-0.19(0.02)^{\star *}$ & $-0.13(0.04)^{\star}$ \\
\hline EJV size & $0.03(0.02)$ & $0.07(0.02)$ & $0.05(0.02)$ & $0.05(0.02)$ & $0.04(0.02)$ & $0.05(0.02)$ & $0.03(0.01)$ & $0.04(0.01)$ & $0.03(0.01)$ \\
\hline Cultural distance & $-0.08(0.04)$ & $-0.07(0.04)$ & $-0.06(0.04)$ & $-0.12(0.04)^{\star}$ & $-0.13(0.04)^{\star}$ & $-0.11(0.04)^{\star}$ & $-0.01(0.02)$ & $-0.04(0.02)$ & $-0.04(0.03)$ \\
\hline Parent introduction & $0.09(0.02)^{\dagger}$ & $0.09(0.02)^{\dagger}$ & $0.10(0.03)^{\dagger}$ & $0.05(0.02)$ & $0.07(0.02)$ & $0.03(0.03)$ & $0.12(0.02)^{\star}$ & $0.13(0.02)^{*}$ & $0.09(0.02)^{\dagger}$ \\
\hline $\begin{array}{l}\text { Chinese experience } \\
\text { at IJVs }\end{array}$ & $0.05(0.04)$ & $0.06(0.04)$ & $0.04(0.04)$ & $0.05(0.04)$ & $0.05(0.04)$ & $0.04(0.04)$ & $0.05(0.03)$ & $0.05(0.03)$ & $0.06(0.03)$ \\
\hline $\begin{array}{l}\text { Foreign experience } \\
\text { at IJVs }\end{array}$ & $0.03(0.04)$ & $0.03(0.04)$ & $0.02(0.04)$ & $0.07(0.05)$ & $0.06(0.05)$ & $0.06(0.05)$ & $0.08(0.05)$ & $0.07(0.05)$ & $0.07(0.05)$ \\
\hline $\begin{array}{l}\mathrm{X} 1 * \text { Goal } \\
\text { incongruence }\end{array}$ & & $-0.06(0.09)$ & & & $-0.02(0.11)$ & & & $-0.05(0.09)$ & \\
\hline $\begin{array}{l}\mathrm{X} 2{ }^{*} \text { Goal } \\
\text { incongruence }\end{array}$ & & $-0.04(0.10)$ & & & $-0.03(0.09)$ & & & $0.05(0.09)$ & \\
\hline $\begin{array}{l}\text { X3 * Goal } \\
\text { incongruence }\end{array}$ & & $-0.02(0.09)$ & & & $-0.03(0.10)$ & & & $0.04(0.07)$ & \\
\hline $\begin{array}{l}\mathrm{X} 1 * \text { Structural } \\
\text { uncertainty }\end{array}$ & & & $0.19(0.09)^{\star *}$ & & & $0.19(0.11)^{\star \star}$ & & & $0.15(0.10)^{\star}$ \\
\hline $\begin{array}{l}\mathrm{X} 2 \text { * Structural } \\
\text { uncertainty }\end{array}$ & & & $0.12(0.07)^{*}$ & & & $0.05(0.09)$ & & & $0.17(0.08)^{\star}$ \\
\hline $\begin{array}{l}\mathrm{X} 3 * \text { Structural } \\
\text { uncertainty }\end{array}$ & & & $0.10(0.09)^{\dagger}$ & & & $0.13(0.11)^{*}$ & & & $0.03(0.06)$ \\
\hline Model $F$ & $27.88^{* * *}$ & $29.79^{* * *}$ & $34.04^{\star * *}$ & $45.58^{\star \star \star}$ & $47.11^{\star \star \star}$ & $49.76^{\star \star \star}$ & $23.04^{\star * \star}$ & $24.04^{* * *}$ & $26.47^{* \star *}$ \\
\hline Adjusted $R^{2}$ & 0.45 & 0.46 & 0.53 & 0.60 & 0.61 & 0.67 & 0.41 & 0.42 & 0.48 \\
\hline$\Delta$ Adjusted $R^{2}$ & & 0.01 & 0.08 & & 0.01 & 0.07 & & 0.01 & 0.07 \\
\hline Hierarchical $F^{c}$ & & 1.44 & $13.28^{\star \star \star}$ & & 1.89 & $16.54^{\star * *}$ & & 1.34 & $10.5^{\star \star \star}$ \\
\hline
\end{tabular}

${ }^{a}$ The entries in the table are the standardized $\hat{a}_{5}$ with standard errors in parentheses, where ${ }^{\dagger} P<0.10 ;{ }^{*} P<0.05 ;{ }^{* *} P<0.01 ;{ }^{* *} P<0.001$

${ }^{\mathrm{b}}$ The mean centering technique was used in all models above to remove the multicollinearity between predictors and interaction terms that contain these predictors. 